\title{
Consumption Smoothing And the Equity Premium
}

$$
\text { by }
$$

Benjamin Eden

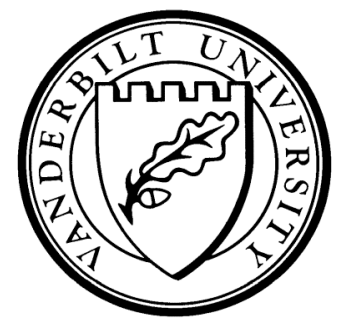

\section{Working Paper No. 10-W11}

November 2010

\section{DEPARTMENT OF ECONOMICS \\ VANDERBILT UNIVERSITY \\ NASHVILLE, TN 37235}

www.vanderbilt.edu/econ 


\title{
CONSUMPTION SMOOTHING AND THE EQUITY PREMIUM
}

\author{
Benjamin Eden 1
}

November 2010

The paper investigates the role of the Intertemporal Elasticity of Substitution (IES) in determining the equity premium. This is done in an overlapping generations economy populated by agents that live for 2 periods and maximize a Kihlstrom-Mirman expected utility function. The equity premium depends both on the demand for smoothing as measured by the inverse of IES and on risk aversion but the first seems to play a more important role. The paper also attempts to understand the difference between the predictions of a 2 periods Kihlstrom-Mirman expected utility and the predictions of a 2 periods Epstein-Zin-Weil utility.

JEL codes: D11, D81, D91, G12

Key words: Fluctuations Aversion, Risk Aversion, Asset Prices, Equity Premium Puzzle, Risk Free Rate Puzzle.

\footnotetext{
1 Vanderbilt University. E-mail: ben.eden@vanderbilt.edu. This paper is a revised version of Eden (2008). The paper benefited from comments and suggestion provided by Dave Backus, Jeff Campbell, Greg Huffman and Jacob Sagi.
} 


\section{INTRODUCTION}

The Intertemporal Elasticity of Substitution (IES) should play a role in determining the equity premium. To motivate this intuition, I consider an economy in which GDP fluctuates over time in a non-random manner but agents are consumption smoothers: They prefer a claim that promises 1 unit of consumption per period to a claim on a fraction of GDP that promises on average 1 unit of consumption per period. In this economy, claims on GDP will be held only if they are cheaper than the fluctuation free asset. This premium arises because of the ordinal properties of the utility function and suggests a role for the IES in the determination of the equity premium.

The IES should also play a role when the economy is hit by iid shocks. The intuition can be captured with the following 2 periods example. I assume that the representative agent's preferences under certainty are of the Leontief type and his preferences under uncertainty can be described by the expected utility function $V\left(\min \left(C_{0}, C_{1}\right)\right)$, where $V^{\prime}>0$ and $C_{i}$ is consumption in period $i=0,1$. Agents are endowed with 2 units of a storable good in the first period of their life. They can achieve a smooth consumption path by storing one unit and getting $C_{0}=C_{1}=1$. The representative agent can also buy a claim on a random future payment with two possible outcomes: 100 or $1-\varepsilon$ with equal probabilities. This claim will not be held if it costs more than 1 unit of consumption for the following reason. If the agent buys the claim at the price of 1 unit, his utility will be $V\left(\min \left(C_{0}=1, C_{1}=100\right)=1\right)$ or $V\left(\min \left(C_{0}=1, C_{1}=1-\varepsilon\right)=1-\varepsilon\right)$. The expected utility is higher with storage: $(1 / 2) V(1)+(1 / 2) V(1-\varepsilon)<V(1)$. The claim on the random payoff will therefore be held only when its price is less than or equal to $1-\varepsilon$. At the price of $1-\varepsilon$, the expected gross rate of return on holding the claim is about 50 and the equity premium is about 4900 percent. The equity premium here does not require risk aversion. ${ }^{2}$

\footnotetext{
2 Eden (1977) used this first order stochastic dominance type reasoning to show that under expected utility insurance type phenomena may arise even in the absence of risk aversion.
} 
Here I attempt to highlight the role of the IES using the Kihlstrom-Mirman (KM, 1974) expected utility approach for separating between IES and risk aversion. I use an overlapping generations economy in which individuals and capital (trees) live for 2 periods and find that the demand for smoothing as measured by the inverse of the IES play a role that seems more important than the role of the risk aversion coefficient.

The role of the IES is not important when using the Selden (1978) utility function which is a 2 period version of the Epstein-Zin $(1989,1991)$ and Weil $(1989,1990)$ (henceforth, EZW) function. ${ }^{3}$ Part of the difference maybe explained by interpreting the risk aversion measures.

In both the $K M$ and the Selden utility function, risk aversion is defined by a parameter that can be eliminated, under certainty, by a monotonic increasing transformation. But the two risk aversion coefficients are not comparable because they characterize the attitude towards different type of bets. The $K M$ risk aversion coefficient characterizes bets on money (wealth), while the Selden risk aversion coefficient characterizes the attitude towards bets on future consumption holding present consumption constant. I refer to the $K M$ risk aversion coefficient as Risk Aversion to Money bets ( $R A M)$ and to the Selden risk aversion coefficient as Risk Aversion to Consumption bets ( $R A C)$.

To compare the two models, I construct a RAC measure for the $K M$ expected utility. This measure depends in roughly equal weights on the demand for smoothing as measured by $1 / I E S$ and the risk aversion to money bets measure $R A M$. Thus, if we interpret the risk aversion coefficient used by Selden through the lens of the expected utility function it has an important IES component in it. This is not however the whole story. In the $K M$ expected utility, the IES has a role even when holding $R A C$ constant.

\footnotetext{
3 This is also the case when using the EZW approach with iid shocks (See Barro [2009]).
} 
Most experimental evidence about the size of the risk aversion coefficient is obtained by asking about the attitude towards bets on money (wealth). We should therefore judge the performance of the two models by the implied $R A M$ coefficient. When $1 / I E S<R A M$ as typically assumed, the parameters in the $K M$ utility function will lead to a $R A C$ measure that is lower than the RAM measure. For example, when IES = 2 and $R A C=4$, the aversion to money bets is $R A M=7.65$.

I attempt to account for a risk free rate in the range of 0-2 percent and an equity premium in the range of 5-9 percent using the $K M$ expected utility function and allowing for rare disasters of the type estimated by Barro (2009). The model can hit the target with various combinations of IES and risk aversion to money bets ( $R A M)$. Among these are: $(I E S=2, R A M=7.65),(I E S=1.1, R A M=7),(I E S=0.5, R A M=5)$ and $(I E S=0.25, R A M=4)$. In general, when the IES coefficient is low we can hit the target with a relatively low $R A M$ coefficient.

I also calculate the welfare cost of economic fluctuations. I find that when $(I E S=2, R A M=7.65, R A C=4)$ the representative agent is willing to pay $0.6 \%$ of his consumption every year, for eliminating the uncertainty about consumption growth. This estimate is an order of magnitude less than the estimate in Barro (2009) who uses the $E Z W$ utility function with $(I E S=2, R A C=4)$.

\section{THE MODEL}

I use an overlapping generation version of the Lucas (1978) tree economy. A new generation is born each period. It consists of identical agents that live for two periods. The representative agent's utility depends on consumption in the first period of his life, $C_{0}$, consumption in the second period of his life, $C_{1}$ and the parameters $\rho, \alpha, \psi>0, \beta>0$. His preferences are described by the following expected utility function. 


$$
U\left(C_{0}, C_{1} ; \rho, \alpha, \psi, \beta\right)=(1 / \psi)\left(\left(C_{0}\right)^{\rho}+\beta\left(C_{1}\right)^{\rho}\right)^{\psi / \rho} \text { when } \rho \neq 0
$$

$$
\begin{aligned}
& U\left(C_{0}, C_{1} ; \rho, \alpha, \psi, \beta\right)=(1 / \alpha)\left(C_{0}\right)^{\alpha}\left(C_{1}\right)^{\alpha \beta} \text { when } \rho=0 \text { and } \alpha \neq 0 \\
& U\left(C_{0}, C_{1} ; \rho, \alpha, \psi, \beta\right)=\ln \left(C_{0}\right)+\beta \ln \left(C_{1}\right) \text { when } \rho=0 \text { and } \alpha=0
\end{aligned}
$$

In most of the paper I work with the intertemporal CES function assuming that $\rho \neq 0$ and the intertemporal elasticity of substitution, IES $=1 / 1-\rho$ is strictly positive. Note that the coefficient $\psi$ (and $\alpha$ ) can be eliminated by an increasing monotonic transformation (multiply by $\psi$ and then raise the expression to the power of $1 / \psi$ ). This coefficient therefore determines the attitude towards risk. More precisely, it determines the attitude towards money bets.

To advance this interpretation, I consider the problem of the representative consumer who makes choices under certainty subject to the budget constraint: $C_{0}+R^{-1} C_{1}=w$, where $R$ is the gross interest rate and $w$ is his initial wealth. The solution to this problem when assuming the CES function is: $C_{i}=k_{i} w$, where $k_{i}$ are constants. Substituting the solution in the utility function we get the indirect utility of wealth function defined by:

$$
V(w)=U\left(C_{0}=k_{0} w, C_{1}=k_{1} w\right)=(1 / \psi)\left(\left(k_{0} w\right)^{\rho}+\beta\left(k_{1} w\right)^{\rho}\right)^{\psi / \rho}=\phi w^{\psi}
$$

where $\phi=(1 / \psi)\left(\left(k_{1}\right)^{\rho}+\beta\left(k_{2}\right)^{\rho}\right)^{\psi / \rho}$ is a constant. We can now define the measure of risk aversion to money bets ( $R A M)$ by:

$$
R A M=-\frac{V^{\prime \prime}(w) w}{V^{\prime}(w)}=1-\psi
$$

I now turn to describe the endowment of the representative agent. He gets $n$ trees in the first period of his life: one tree from each type. Like the representative agent, each tree lives for two periods. For the generation born at time $t$, the endowment of $n$ trees 
yield a total of $\lambda_{t}$ units of consumption (fruits) in the first period of their lives, where the coefficient $\lambda_{t}$ represents the productivity of the generation born at $t$.

The amount of fruits (output) in the second period is a random variable that can take $S$ possible realizations indexed $s=1, \ldots, S$. The probability that realization $s$ (state $s$ ) will occur is $\Pi_{s}$ and does not change over time. Type $i$ tree that was "born" at time $t$, yields $\lambda_{t} d_{i s}$ units in the second period of its life, in state $s$.

There is a market for trees after the distribution of their first period dividends. The price of type $i$ tree at time $t$ is $p_{i t}$. I use $A_{i t}$ to denote the quantity of type $i$ tree purchased by the agent born at time $t, C_{0 t}$ to denote his first period consumption and $C_{1 s t}$ to denote his second period consumption in state $s$. His budget constraint is:

$$
\begin{gathered}
C_{0 t}+\sum_{i=1}^{n} p_{i t} A_{i t}=\lambda_{t}+\sum_{i=1}^{n} p_{i t} \\
C_{1 s t}=\lambda_{t} \sum_{i=1}^{n} d_{i s} A_{i t}
\end{gathered}
$$

And he solves the following problem:

$$
\max _{A_{i t}} \sum_{s=1}^{S} \Pi_{s} U\left(C_{0 t}, C_{1 s t}\right) \text { s.t. (4) and (5). }
$$

The first order conditions for this problem are:

$$
\sum_{s=1}^{S} \Pi_{s}\left(-U_{0 s} p_{i t}+U_{1 s} \lambda_{t} d_{i s}\right)=0
$$

When $\rho \neq 0$ the utility function is given by $U\left(C_{0}, C_{1}\right)=(1 / \psi)\left(\left(C_{0}\right)^{\rho}+\beta\left(C_{1}\right)^{\rho}\right)^{\psi / \rho}$, the asset pricing formula (7) is: 


$$
p_{i t}=\beta \lambda_{t} \frac{\sum_{s=1}^{S} \Pi_{s}\left[1+\beta\left(D_{s}\right)^{\rho}\right]^{\frac{\mu-1}{\rho}}\left(D_{s}\right)^{\rho-1}\left(d_{i s}\right)}{\sum_{s=1}^{S} \Pi_{s}\left[1+\beta\left(D_{s}\right)^{\rho}\right]^{\frac{\underline{\mu}}{\rho}-1}},
$$

where $D_{s}=\sum_{i=1}^{n} d_{i s}$.

Note that the gross rates of return $R_{i t}=\frac{\lambda_{t} \sum_{s=1}^{S} \Pi_{s} d_{i s}}{p_{i t}}$ do not depend on the technology parameter $\lambda_{t}$ and do not change over time. In what follows I therefore assume $\lambda_{t}=1$.

\section{CALIBRATION}

I start with the case in which the length of the period in the model is one year and $\beta=0.96$. Following Barro (2009) I assume that disasters may occur with probability $1.7 \%$. Thus, with probability $1-0.017$ the aggregate amount of fruits is determined by a normal lottery and with probability 0.017 it is determined by a disaster lottery. I assume that the gross rate of consumption growth when getting the normal lottery has two possible realizations: 1.005 and $1.045(1.025 \pm 0.02)$ with equal probabilities. The gross rate of growth when getting the disaster lottery has two possible realizations:

$0.73 \pm 0.2066$. The mean of the disaster lottery $(0.73)$ is consistent with Barro's estimate. The standard deviation of roughly $20 \%$ is consistent with the certainty equivalent calculations in Barro. The compound lottery therefore has 4 possible realizations: 1.005 with probability $0.4915,1.045$ with probability $0.4915,0.5234$ with probability 0.085 and 0.9366 with probability 0.085 . As in Barro, the average rate of growth in GDP is $2 \%$, the average rate of growth of GDP conditional on being in normal times (i.e. getting the normal lottery) is $2.5 \%$ and the standard deviation of the rate of growth when getting the normal lottery is $2 \%$.

I look for parameters that yield a risk free rate in the range of 0-2 percent and an equity premium in the range of 5-9 percent. The estimates in Barro (2009) of a risk free 
rate of $1.4 \%$ and an equity premium of $6.5 \%$ are in this range. There is however a debate about the magnitude of the rates of return. See for example, McGrattan and Prescott (2003). I therefore use a range rather than a point as my target.

The empirical literature did not reach a consensus about the magnitude of the IES . Hall (1988), Campbell and Mankiw (1989) and Beaudry and Wincoop (1996) provide estimates of the IES between zero and one. Vissing-Jorgensen and Attanasio (2003) estimate IES >1. Barro (2009) follows Gruber (2006) and assumes IES =2.

Bansal and Yaron (2004) and Barro (2009) argue that IES $<1$ leads to the result that increase in uncertainty cause an increase in asset prices. They find this result to be implausible. I do not see why an increase in uncertainty cannot lead to an increase in savings and an increase in asset prices. Here I consider the range $0.2 \leq I E S \leq 3$.

I follow Mehra and Prescott (1985) and assume that $0 \leq R A M \leq 10$. Many economists think that the risk aversion coefficient is less than 3. Lucas (2003), for example, assumes that it is 1 . As a result an implicit "goodness of fit" measure has emerged. A model is considered to provide a better account for the observed rates of return if it can do it with a relatively low RAM. In our case, a low IES allows us to account for the observed rates with a relatively low $R A M$.

Figure 1a assumes $I E S=2$ and plots the gross rate of return on the market portfolio (calculated from [8] by assuming $d_{i s}=D_{s}$ ), the gross rate of return on the riskless asset (calculated from [8] by assuming $d_{i s}=1$ ) and the difference between the two - the equity premium. When $R A M=9$, the risk free rate is $1.25 \%$ and the equity premium is $6.9 \%$. When $R A M=10$, the risk free rate is $0.07 \%$ and the equity premium is 9.1\%. Figure $1 \mathrm{~b}$ plots the rates of returns when $I E S=1.1$. In this case, when $R A M=7$, the risk free rate is $1.4 \%$ and the equity premium is $5 \%$. Figure $3 \mathrm{c}$ assumes $I E S=0.5$. When $R A M=5.3$, the risk free rate is $0.7 \%$ and the equity premium is $5.1 \%$. 
Welfare cost: When $R A M=10$ and $I E S=2$ the agent is willing to swap the random income for a certain income that is $1.1 \%$ less than the mean of the distribution. When $R A M=6$ and $I E S=2$ the number is about $0.4 \%$. When $R A M=6$ and $I E S=0.8$ the welfare cost is $0.6 \%$. When $R A M=1.1$ and $I E S=1.7$ the welfare cost is $0.07 \%$. These estimates are described in Figure 2a. The welfare cost of eliminating "normal fluctuations" in GDP is tiny. Figure $2 \mathrm{~b}$ illustrates. When $R A M=6$ and $I E S=1.15$, the welfare cost of replacing the normal lottery by its mean is only $0.03 \%$ (three percent of 1 percent). In both Figures the welfare cost is decreasing with the IES holding the RAM constant. 


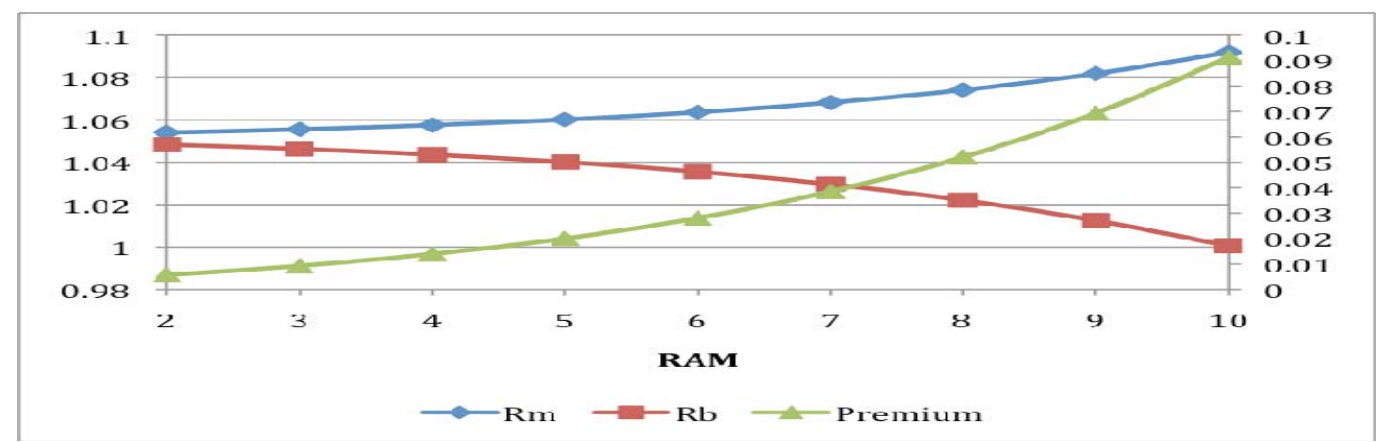

a. $I E S=2$

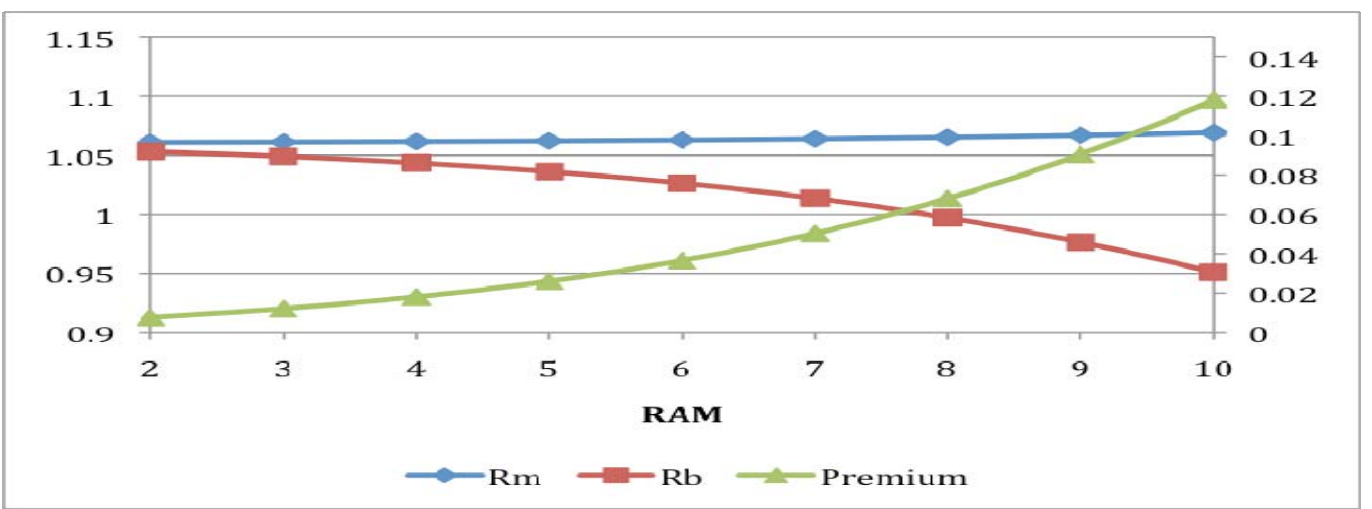

b. $I E S=1.1$

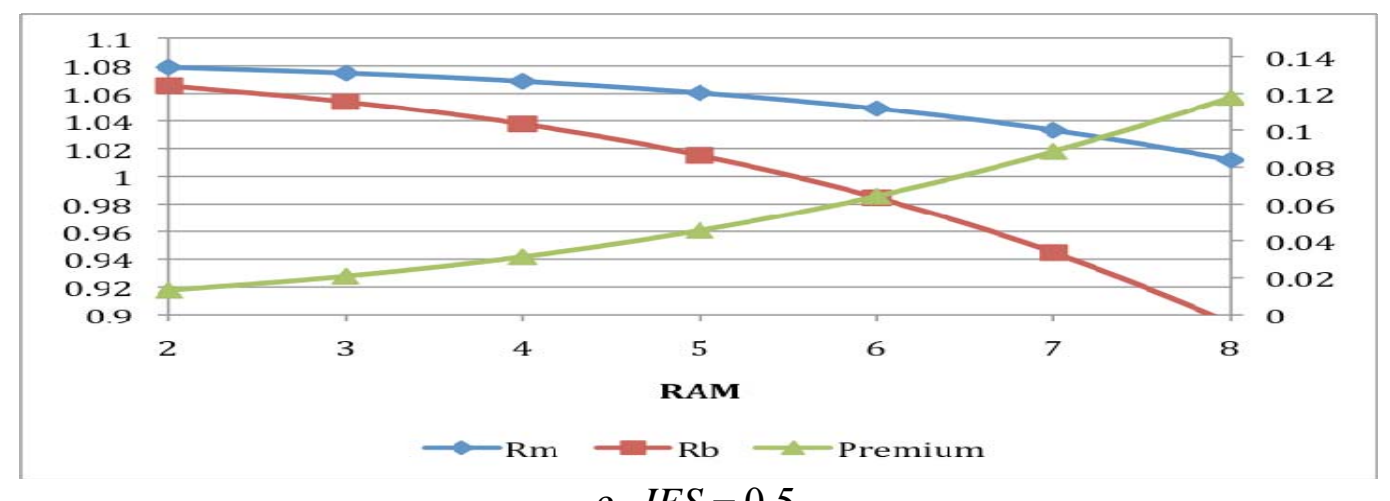

c. $I E S=0.5$

Figure 1: Predicted rates of return (the gross rates of return are on the left axis, the equity premium is on the right axis; $R_{m}$ is the rate of return on the market portfolio; $R_{b}$ is the risk free rate) 


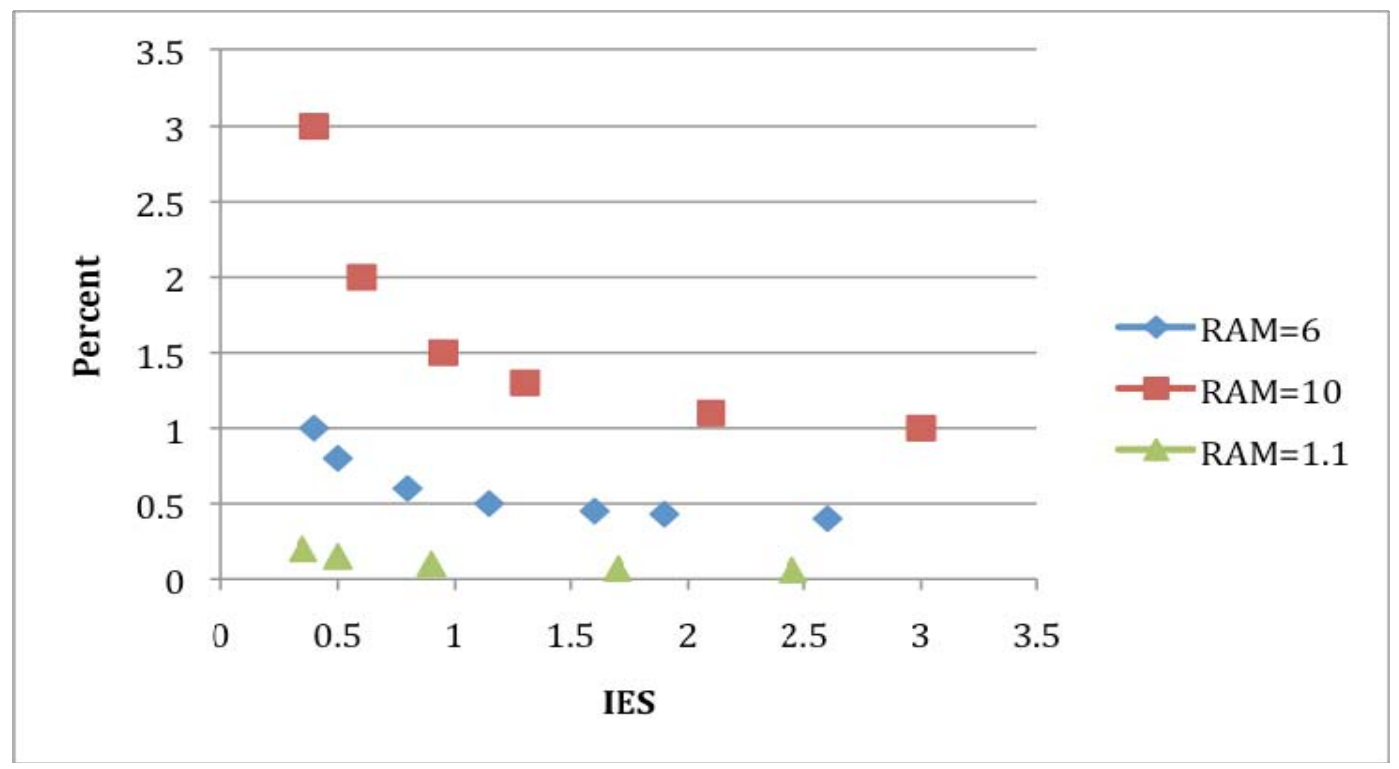

a. The Welfare Cost of Eliminating All Risk

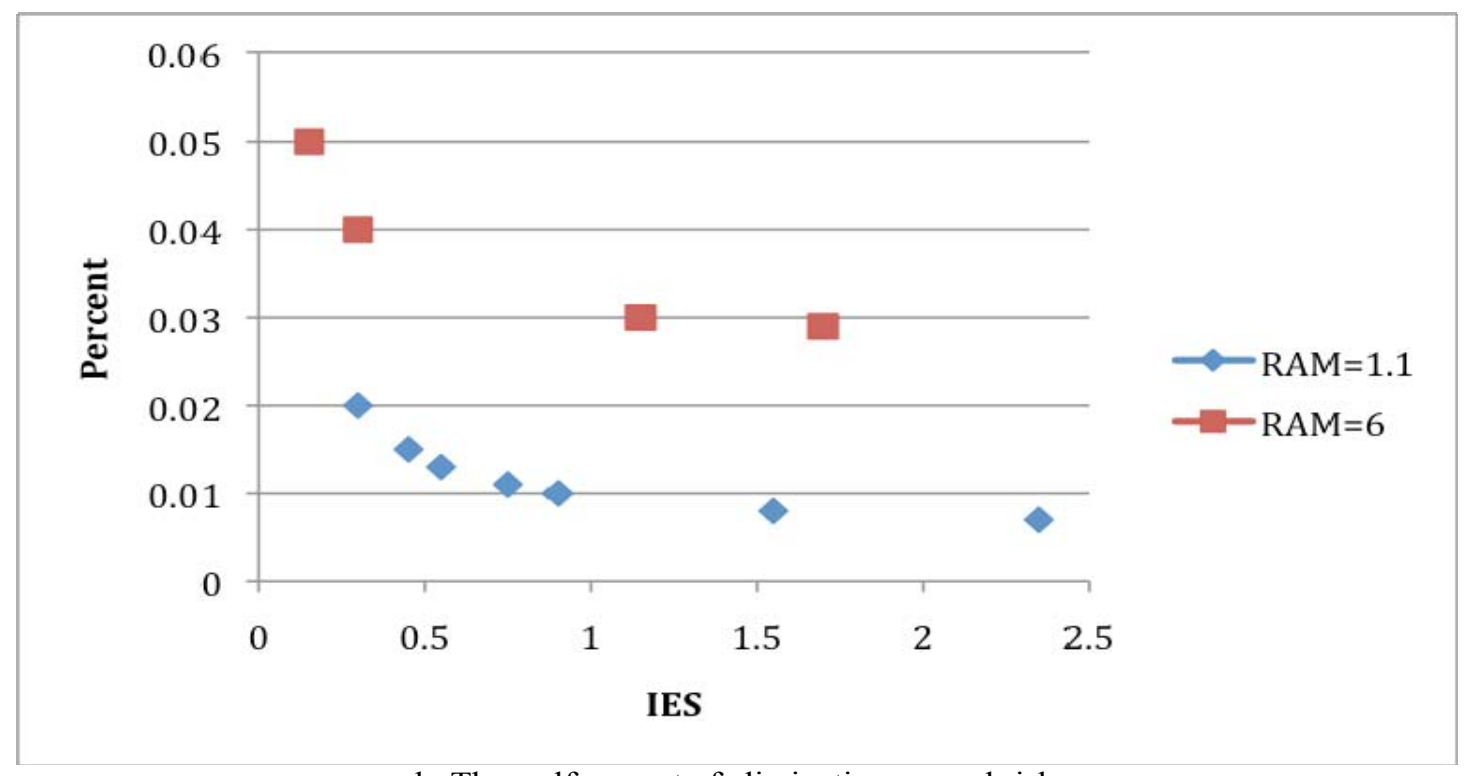

b. The welfare cost of eliminating normal risk

Figure 2: Welfare cost (the percentage of income that the representative agent is willing to give up to replace the random outcome by its mean) 


\section{THE SELDEN UTILITY FUNCTION}

In the two periods case, the Epstein-Zin-Weil approach is the same as Selden (1978). Selden evaluates consumption paths in which there is uncertainty only on second period consumption. This is done in two stages. He first substitutes a certainty equivalent for the random future consumption and then use an "aggregator function" to evaluate current consumption and the certainty equivalence of future consumption.

To illustrate, let $C$ denotes current consumption and $x$ denotes a random future consumption. The Selden consumer first uses the certainty equivalence function $\mu$ to convert $x$ to a scalar: $Z=\mu(x)$. He then uses the aggregator function $G(C, Z)$ to evaluate the certainty equivalent consumption path. In this formulation IES is determined by the properties of the aggregator function $G$ while aversion to bets in terms of future consumption is determined by the properties of the certainty equivalence function $\mu$.

I assume a power certainty equivalence function:

$$
\mathrm{Z}=\left(E x^{\sigma}\right)^{1 / \sigma} \text { where } 0 \neq \sigma<1 \text {. }
$$

And a CES aggregator function:

$$
G(C, Z)=\left(C^{\rho}+\beta Z^{\rho}\right)^{\frac{1}{\rho}}=\left(C^{\rho}+\beta\left[\left(E x^{\sigma}\right)^{\rho / \sigma}\right]\right)^{\frac{1}{\rho}}
$$

Under certainty the coefficient $\sigma$ drops out and therefore this coefficient has been called the risk aversion coefficient. The coefficient of relative risk aversion with respect to bets in terms of future consumption is $R A C=-\frac{\mu^{\prime \prime} x}{\mu^{\prime}}=1-\sigma$. The representative agent's problem is: 


$$
\max _{A_{i}}\left(\left[1+\sum_{i=1}^{n} p_{i}-\sum_{i=1}^{n} p_{i} A_{i}\right]^{\rho}+\beta\left[\sum_{s=1}^{s} \Pi_{s}\left(\sum_{i=1}^{n} d_{i s} A_{i}\right)^{\sigma}\right]^{\frac{\rho}{\sigma}}\right)^{\frac{1}{\rho}}
$$

Substituting the market clearing conditions in the first order conditions for this problem, leads to the following asset pricing formula.

$$
p_{i}=\beta\left\{\left[\sum_{s=1}^{S} \Pi_{s}\left(D_{s}\right)^{\sigma}\right]^{1 / \sigma}\right\}^{\rho-1}\left[\sum_{s=1}^{S} \Pi_{s}\left(D_{s}\right)^{\sigma}\right]^{\frac{1}{\sigma}-1} \sum_{s=1}^{S} \Pi_{s}\left(D_{s}\right)^{\sigma-1} d_{i s},
$$

Figure 3 compares the predictions of the two models when IES $=2$ and their respective measures of risk aversion $(R A M=1-\psi$ for $K M$ and $R A C=1-\sigma$ for Selden $)$ are the same. As we can see there are large differences in the predictions of the two models. The equity premium is an order of magnitude higher and the risk free rate is much lower under the Selden utility function. For example, when both measures of risk aversion are 10 the equity premium under Selden is close to $50 \%$ while it is only $10 \%$ under the $K M$ utility function. 


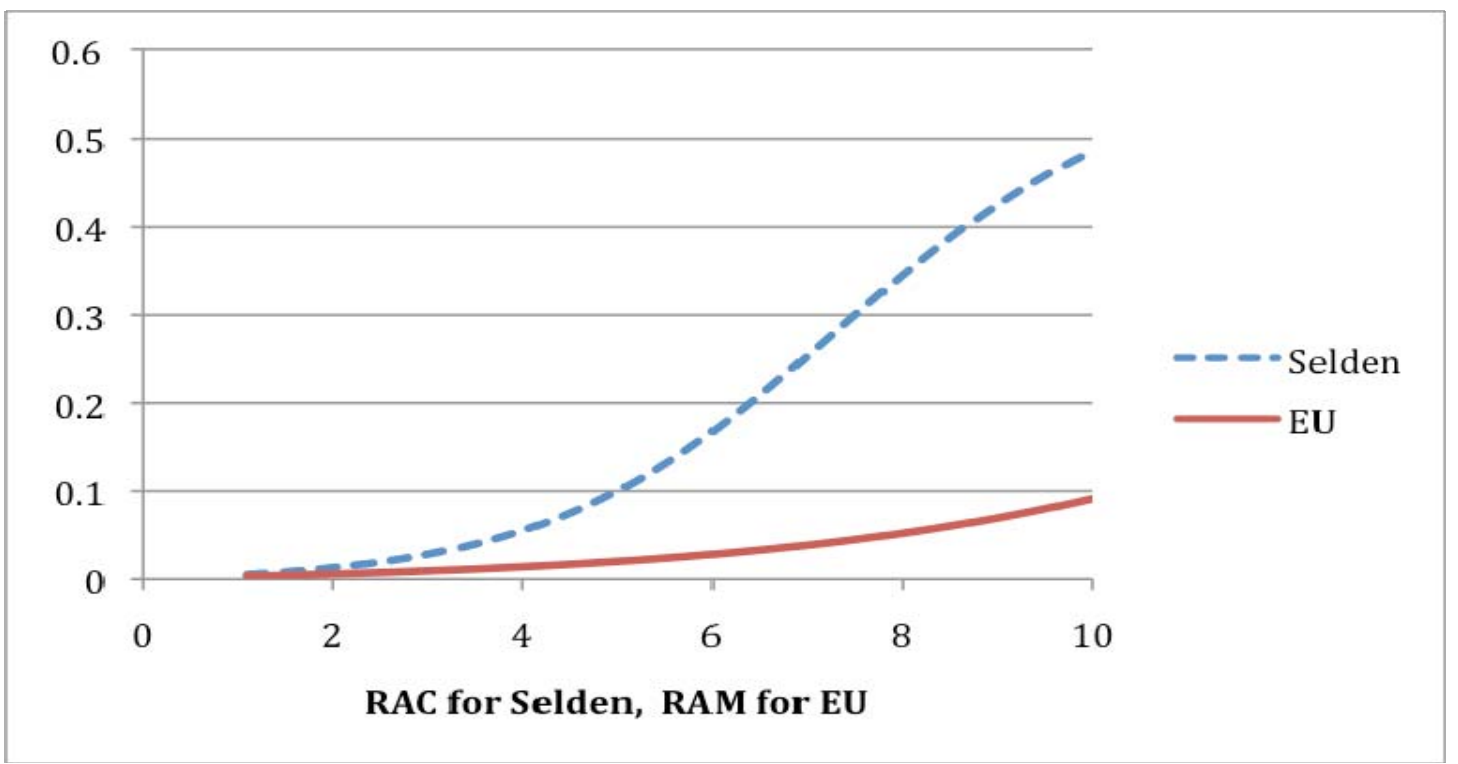

a. Equity Premium

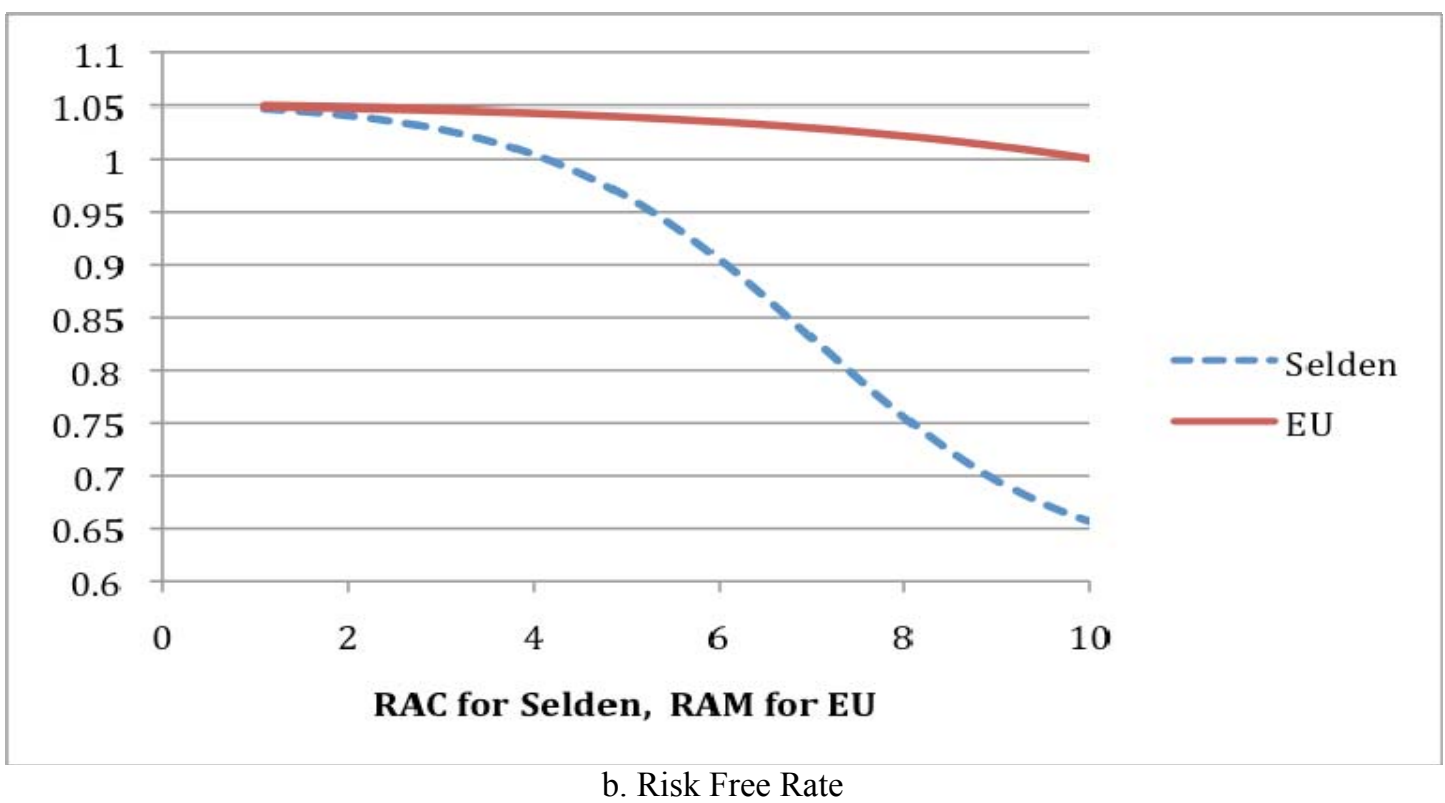

Figure 3: The Predictions of the two models when $I E S=2$ and $R A M=1-\psi=R A C=1-\sigma$ 


\section{COMPARABLE RISK AVERSION MEASURES}

The results of the two models are very different because the measures of risk aversion are not comparable. The Selden measure of risk aversion describes the attitude towards bets on future consumption (holding current consumption constant). The KM measure of risk aversion describes the attitude towards bets on money.

The distinction between the two types of bets can be illustrated with the help of Figure 4 that assumes a zero interest rate. The consumer starts at point $E$ that maximizes his utility when his wealth is 4 . He now considers a money bet in which he can win or loose one unit. If he wins he will choose point $B$. Otherwise, he will choose point $A$. This money bet may thus be described as having two outcomes: $A$ or $B$. A bet in terms of future consumption that holds current consumption at the level $C_{0}=2$ and is of the same relative size as the money bet just described has the outcomes: point $G$ or point $F$.

Under expected utility, the indifference map does not provide complete information about the attitude towards risk. To illustrate, I denote the level of utility from the points $(A, E, B)$ by $(a, e, b)$, respectively. From observing the indifference map we know that: $a<e<b$ but we do not know by how much. The consumer will prefer a wealth of 4 with certainty to a random wealth $\{3$ or 5 with equal probabilities $\}$ if $e>(a+b) / 2$. Otherwise, he will prefer the bet.

Nevertheless, the indifference map provides information about choice under uncertainty whenever the first order stochastic dominance criterion can be applied. For example, under expected utility the agent with the indifference curves in Figure 4, will prefer point $E$ with certainty to a bet that has two possible outcomes: Point $J$ and point $H$, because $E$ is preferred to each possible outcome. ${ }^{4}$ This prediction cannot be made under the Selden utility function that does not respect first order stochastic dominance.

\footnotetext{
${ }^{4}$ Van den Heuvel (2007) shows that under the expected utility a consumer who prefers the actuarially fair money bet $b_{1}=\{A$ or $B\}$ to the actuarially fair bet $b_{2}=\{H$ or $J\}$ must have IES $>1$.
} 
This difference in the applicability of first order stochastic dominance criterion, provides a clue to why the IES plays an important role under expected utility but not under the Selden utility.

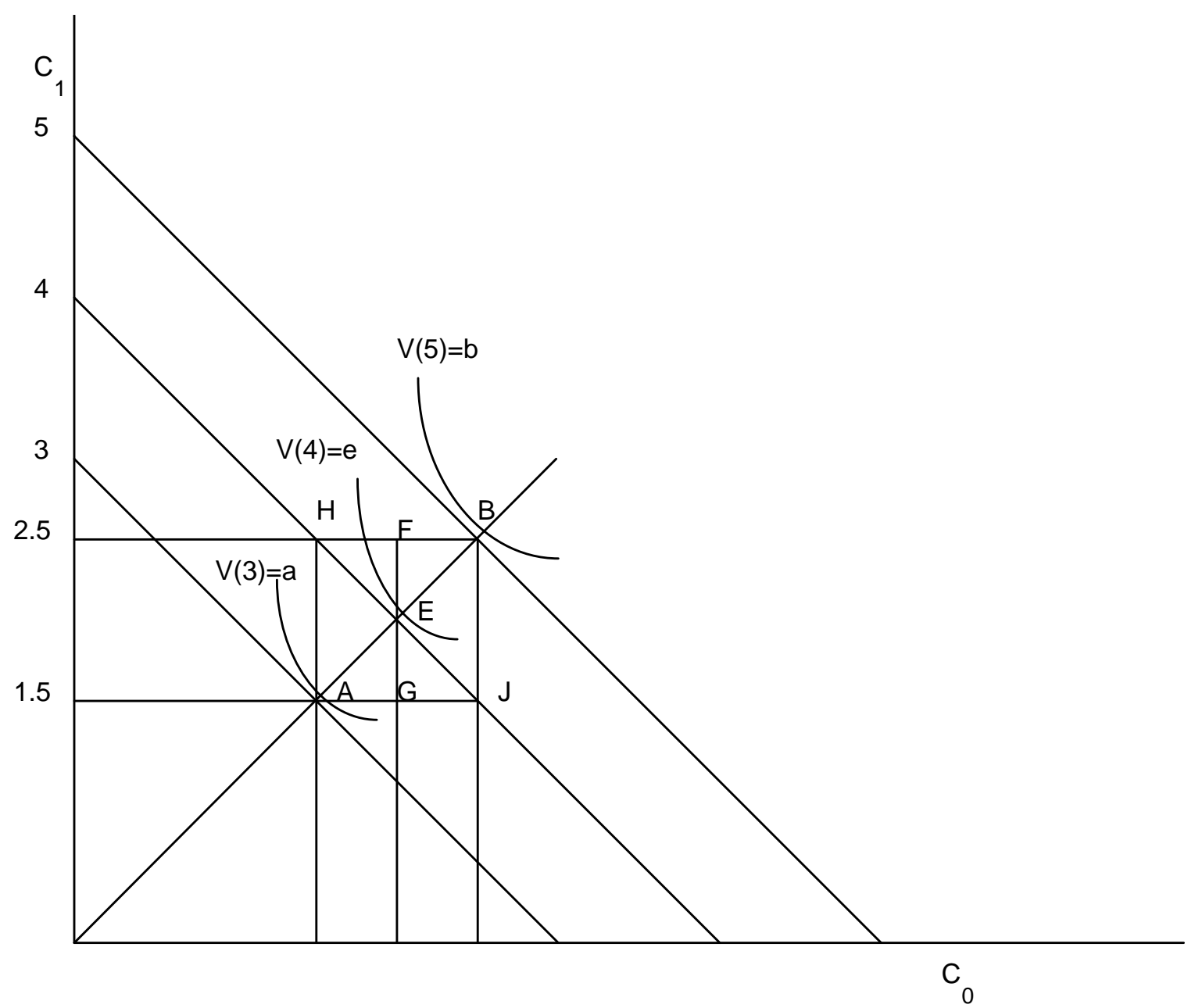

Figure 4

Under the expected utility the coefficient that describes the attitude towards bets in terms of second period consumption is:

$$
R A C=-\frac{U_{22} C_{1}}{U_{2}}=1-\rho+\frac{(\rho-\psi) \beta}{(1+\beta)}=(1-\eta) \frac{1}{I E S}+\eta R A M
$$


where $\eta=\frac{\beta}{1+\beta}, U_{2}=\widetilde{\alpha} / \Upsilon_{1}$ is the first partial derivative and $U_{22}=\partial_{2} / \Upsilon_{1}$ is the second partial derivative. ${ }^{5}$ Note that $R A C$ is a weighted average of $1 / 1 E S$ and $R A M$. In the special case of the standard power utility function the two are equal. When $1 / 1$ IES $>R A M$, the $R A C$ measure is higher than the RAM measure and the opposite is true when $1 / 1 E S<R A M$. For example, when $\beta=1, I E S=2$ and $R A M=10$, we get: $R A C=5.25$. I argue that the $R A C$ measure is comparable to the Selden risk aversion coefficient because the Selden uncertainty is about future consumption.

Figures 5 and 6 compare the predictions of the two models when both models have the same IES and the same RAC measure (using [13] to obtain the RAC measure for the expected utility case). Figure 5a and $6 \mathrm{a}$ assume $I E S=2$ and may be compared to Figure 3. We see that when the measure of risk aversion RAC is the same for both models the differences between the predictions of the two models is much smaller than the difference that arises when the cardinal measures of risk aversion (i.e. measures that can be eliminated under increasing monotonic transformations) are the same.

\footnotetext{
${ }^{5}$ It may help to define the utility from second period consumption, holding first period consumption at the level $C_{0}=\bar{C}_{0}$, by: $F\left(C_{1}\right)=U\left(\bar{C}_{0}, C_{1}\right)$. In this case, the relative risk aversion measure in (13) is: $R A C=-\frac{F^{\prime \prime}\left(C_{1}\right) C_{1}}{F^{\prime}\left(C_{1}\right)}$
} 


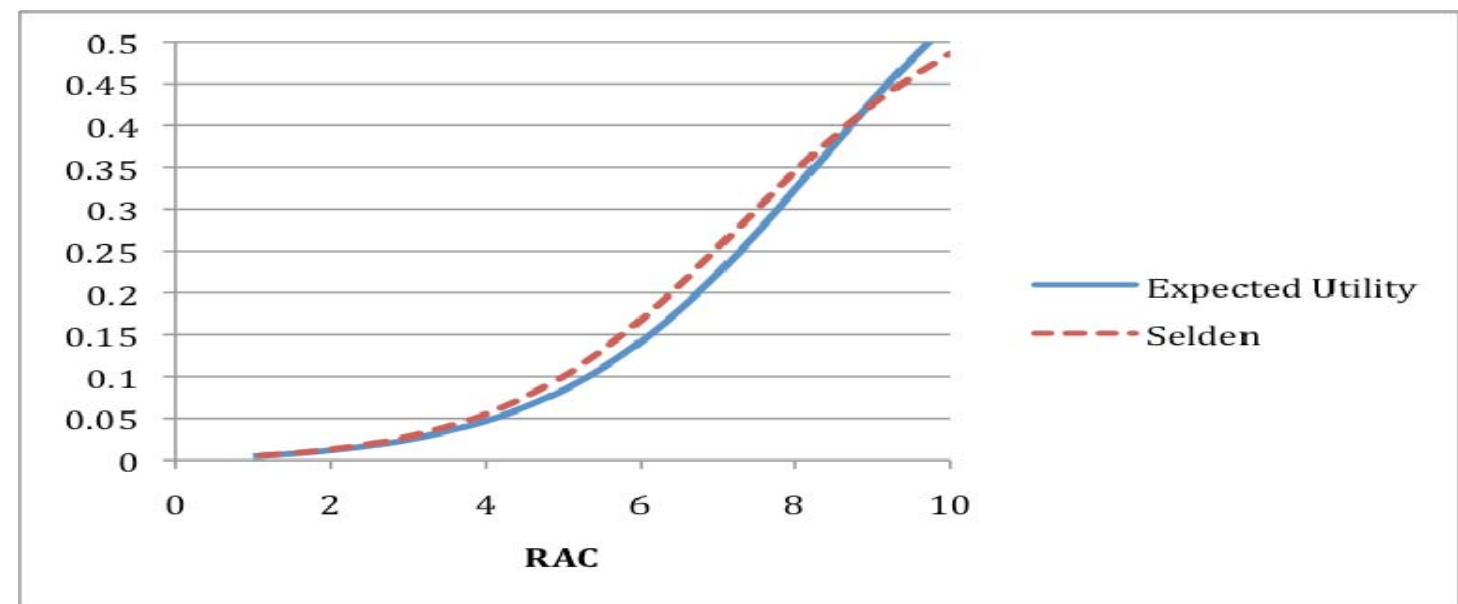

a. $I E S=2$

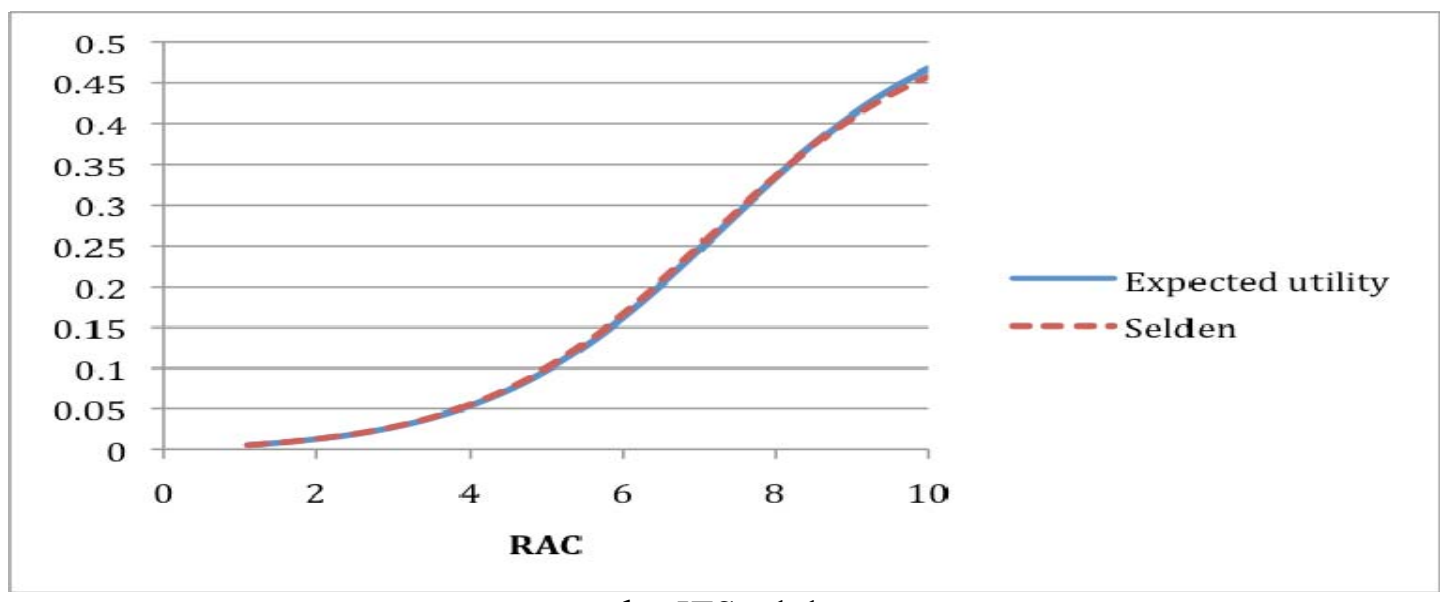

b. $I E S=1.1$

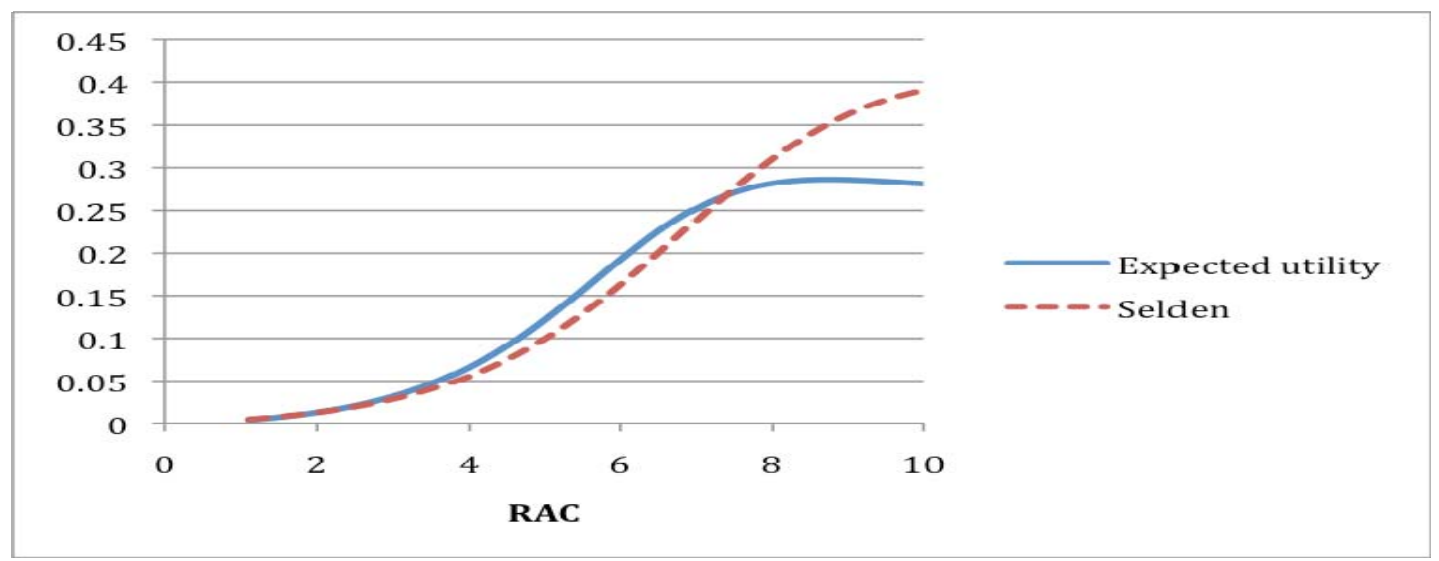

c. $I E S=0.5$

Figure 5: The Equity Premium when the Measure of Risk Aversion are Comparable 


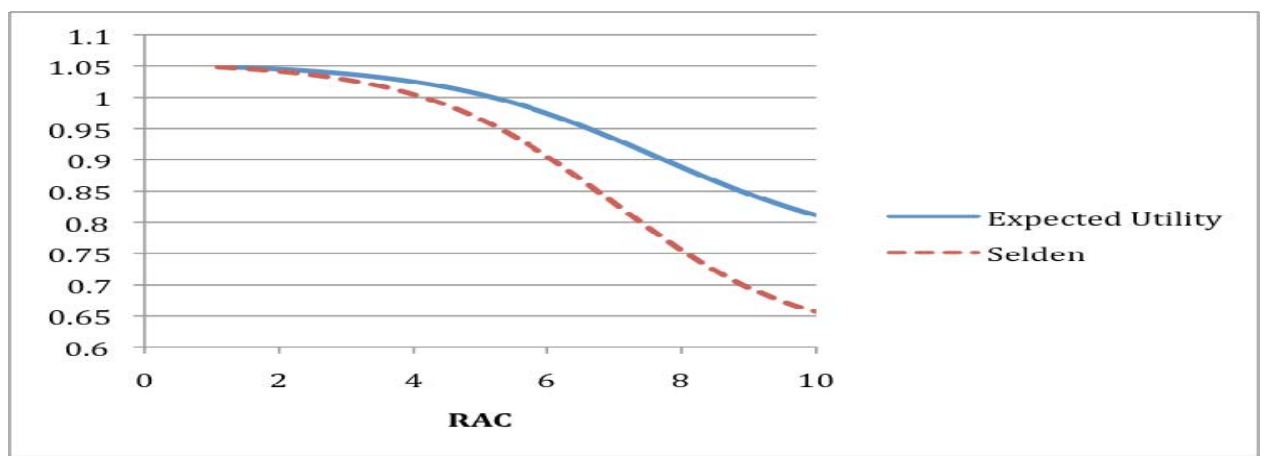

a. $I E S=2$

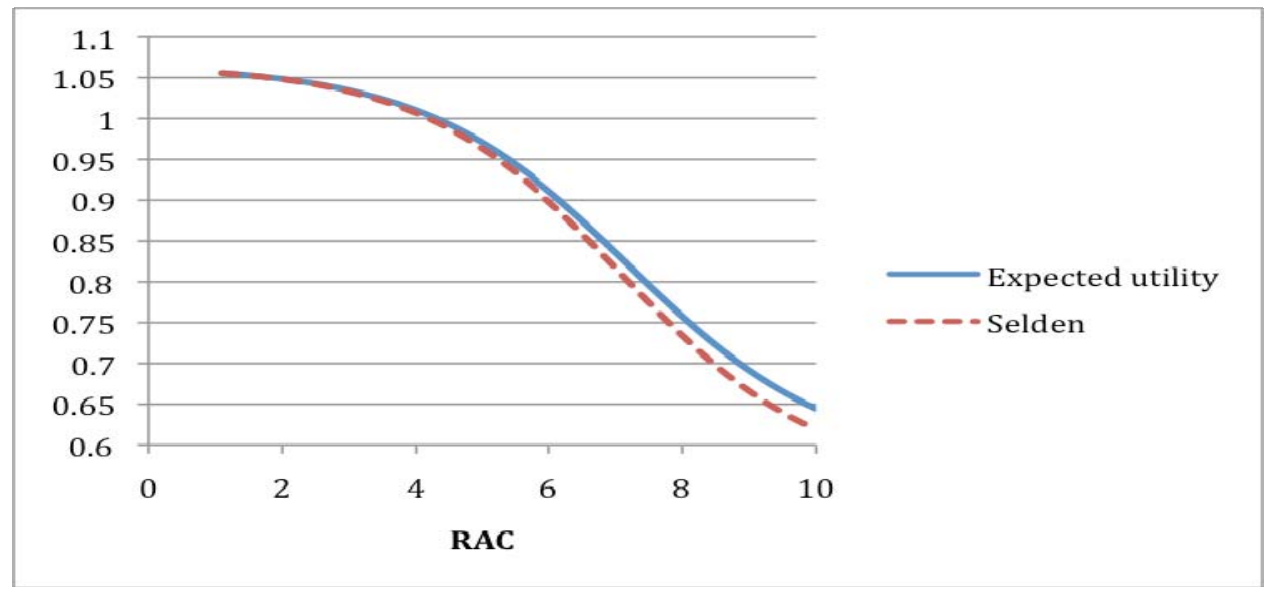

b. $I E S=1.1$

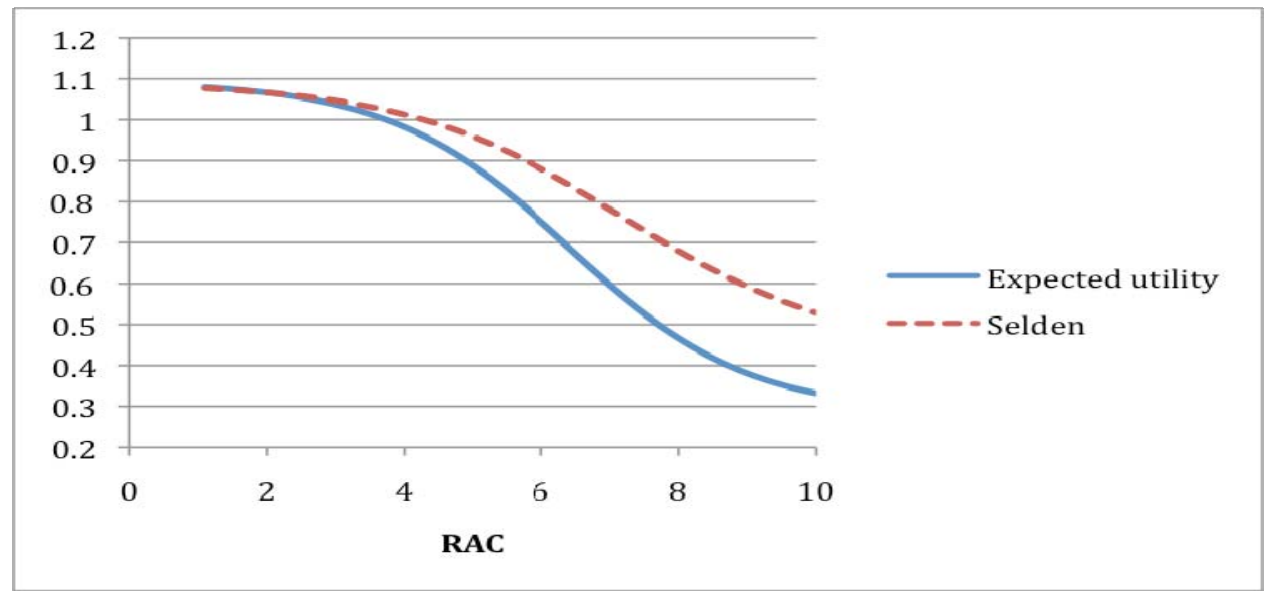

c. $I E S=0.5$

Figure 6: The Risk Free Rate when the Measures of Risk Aversion are Comparable

Welfare cost under the Selden utility function: When $R A C=4$ the consumer is indifferent between the assumed random second period income and a certainty equivalent 
second period income equal to $0.9855 E\left(C_{1}\right)$. The certainty equivalent is thus $1.45 \%$ lower than the mean and this is the welfare cost in terms of second period income. The cost in terms of every year income is $1-y$ where $y$ is the solution to:

$$
\left((y)^{\rho}+\beta\left(y E\left(C_{1}\right)\right)^{\rho}\right)^{1 / \rho}=\left(1+\beta\left(0.9855 E\left(C_{1}\right)\right)^{\rho}\right)^{1 / \rho} .
$$

I find that the welfare cost under the Selden utility function is not sensitive to the choice of IES. The every period welfare cost is $0.7 \%$ when $R A C=4,1.9 \%$ when $R A C=6$ and close to $8 \%$ when $R A C=10$.

Under the expected utility with IES $=2$, I get a welfare cost of $0.6 \%$ when $R A C=4(R A M=7.65)$, a welfare cost of $1.6 \%$ when $R A C=6(R A M=11.75)$ and a welfare cost of $6.3 \%$ when $R A C=10(R A M=19.9)$. Reducing the IES will increase the welfare cost for the expected utility but will not change it for the Selden utility.

\section{THE COBB DOUGLAS CASE}

Figures 5 and 6 suggest that the two approaches yields the same predictions when $I E S=1$, which is the Cobb-Douglas case. I now show that this is indeed the case. I start with the expected utility specification: $U\left(C_{0}, C_{1} ; \rho, \alpha, \psi, \beta\right)=(1 / \alpha)\left(C_{0}\right)^{\alpha}\left(C_{1}\right)^{\alpha \beta}$. In this case, $R A M=1-\alpha(1+\beta)$ and $R A C=1-\alpha \beta$.

Using the first order conditions (7), the market clearing conditions $C_{0}=1$, $C_{1 s}=D_{s}$ we arrive at the equilibrium condition:

$$
p_{i}=\beta \frac{\sum_{s=1}^{S} \Pi_{s}\left(D_{s}\right)^{\alpha \beta-1} d_{i s}}{\sum_{s=1}^{S} \Pi_{s}\left(D_{s}\right)^{\alpha \beta}}=\beta \frac{\sum_{s=1}^{S} \Pi_{s}\left(D_{s}\right)^{-R A C} d_{i s}}{\sum_{s=1}^{S} \Pi_{s}\left(D_{s}\right)^{1-R A C}}
$$

I now turn to the Selden utility function when the aggregator function is Cobb-Douglas: 
$G(C, Z)=\left(\frac{1}{\alpha}\right) C^{\alpha} Z^{\alpha \beta}=(1 / \alpha) C^{\alpha}\left(E x^{\sigma}\right)^{\alpha \beta / \sigma}$. The problem of the representative agent when using this function is: $\max _{A_{i}}(1 / \alpha)\left[1+\sum_{i=1}^{n} p_{i}-\sum_{i=1}^{n} p_{i} A_{i}\right]^{\alpha}\left[\sum_{s=1}^{S} \Pi_{s}\left(\sum_{i=1}^{n} d_{i s} A_{i}\right)^{\sigma}\right]^{\alpha \beta / \sigma}$.

The pricing formula obtained by substituting the market clearing conditions in the first order condition is:

$$
p_{i}=\frac{\beta \sum_{s=1}^{S} \Pi_{s}\left(D_{s}\right)^{\sigma-1} d_{i s}}{\sum_{s=1}^{S} \Pi_{s}\left(D_{s}\right)^{\sigma}}=\frac{\beta y \sum_{s=1}^{S} \Pi_{s}\left(D_{s}\right)^{-R A C} d_{i s}}{\sum_{s=1}^{S} \Pi_{s}\left(D_{s}\right)^{1-R A C}}
$$

Note that (14) is the same as (15), once we express the price in terms of RAC. This says that the two models predict the same prices when both have the same $R A C$.

Welfare calculations are also the same when RAC is held constant. When assuming $\sigma=\alpha \beta$, the $R A C$ measure is the same for both utility functions, welfare under the expected utility is $(1 / \alpha)\left(C_{0}\right)^{\alpha} E\left(x^{\alpha \beta}\right)=(1 / \alpha)\left(C_{0}\right)^{\alpha} E\left(x^{1-R A C}\right)$ and welfare under the Selden utility function is $(1 / \alpha) C^{\alpha}\left(E x^{\sigma}\right)^{\alpha \beta / \sigma}=(1 / \alpha) C^{\alpha} E\left(x^{1-R A C}\right)$. Since the functions are identical the certainty equivalents are the same. We have thus shown the following Claim.

Claim: In the Cobb-Douglas case, the two approaches yield the same predictions about asset prices and the same welfare cost calculations, when the assumed parameters imply the same RAC measures.

Since the welfare cost under Selden is not sensitive to changes in the IES and the welfare cost under expected utility is decreasing in the IES, we can use the claim to make the following comparison: The welfare cost under Selden is higher (lower) than the welfare cost under expected utility when IES is higher (lower) than unity and RAC is held constant. ${ }^{6}$

\footnotetext{
6 The welfare cost under expected utility may be much less than the welfare cost under the Selden utility
} function when the cardinal measure of risk aversion are held constant. Under the expected utility with 
The Cobb Douglas case is also useful for characterizing the difference in the predictions about the risk free rate, when holding $R A C$ constant. Figure 6 suggests that when IES $>1$, the predicted risk free rate is higher under expected utility but the opposite is true when $I E S<1$. We cannot make an analogous statement about the equity premium (Figure 5).

Finally, the Cobb Douglas case is a useful benchmark for describing the relationship under expected utility between $R_{m}$ and RAM holding the IES constant. In the Cobb Douglas case with IES $=1, p_{i}=\beta y$ and does not depend on the distribution of future dividends. The expected rate of return on the market portfolio is: $R_{m}=D / \beta$ where $D=\sum_{s=1}^{S} \Pi_{s} D_{s}$ is the expected rate of consumption growth. In this case changes in $R A M$ do not affect the expected rate of return on holding the market portfolio. This is not the case when $I E S \neq 1$. As can be seen from Figure 1 , when $I E S=2, R_{m}$ increases with risk aversion and the opposite occurs when $I E S=0.5$. The behavior of $R_{m}$ when $I E S<1$ may appear counter intuitive when thinking about the risk free rate as a constant. What actually happens is that when $R A M$ increases the risk free rate decreases, and decreases more sharply when $I E S<1$. Therefore, the expected rate of return on the market portfolio may decrease with $R A M$ even when the equity premium increases with $R A M$.

\section{THE ROLE OF IES IN DETERMINING THE EQUITY PREMIUM}

Changes in IES affect the equity premium in the $K M$ expected utility case but have almost no effect on the equity premium in the Selden case. Figure 7a illustrates by plotting the equity premium as a function of IES for two levels of cardinal risk aversion measures: $(3.6,4)$ for Selden and $(5.3,7.65)$ for the $K M$ expected utility. The $R A C$ measure of 3.6 for Selden is comparable to the $R A M$ measure of 5.3 for the $K M$

IES between 1 and 2, the welfare cost is $0.5 \%$ when $R A M=6$. This is about a quarter of the welfare cost when using a Selden utility function with $R A C=6$. 
expected utility when IES $=0.5$. The $R A C$ measure of 4 for Selden is comparable to the $R A M$ measure of 7.65 for the $K M$ expected utility when $I E S=2$. Figure $7 \mathrm{~b}$ plots the equity premium as a function of $1 /$ IES which seems to be a better measure for fluctuations aversion because the relationship is close to linear especially for the lower $R A M$.

To advance the interpretation of $1 / 1 E S$ as a measure of fluctuation aversion, Figure 8 calculates the Fluctuations Premium as the amount that the consumer is willing to give in terms of average consumption for substituting a non-smooth consumption path $\left(C_{0}, C_{1}\right)$ for a smooth consumption path $(C, C)$. The smooth equivalent consumption $C$ yields the same utility as the non-smooth path: $\left(\left(C_{0}\right)^{\rho}+\beta\left(C_{1}\right)^{\rho}\right)^{1 / \rho}=\left((C)^{\rho}+\beta(C)^{\rho}\right)^{1 / \rho}=((1+\beta))^{1 / \rho} C$ and the premium is calculated as $\left(C_{0}+C_{1}\right) / 2-C$. We see that the fluctuations premium is almost a linear function of our measure of fluctuations aversion $1 / 1$ IES, and increasing the rate of consumption growth $g$ leads to an increase in the premium.

We have seen that under expected utility the equity premium depends both on the cardinal measure $R A M$ and fluctuations aversion as measured by $1 / 1 E S$. Can we explain the role of the fluctuation aversion by its role in determining the $R A C$ measure? To answer this question I plot in Figure 9 the equity premium as a function of IES and $1 / 1 E S$ while holding (a) RAC constant and (b) RAM constant. ${ }^{7}$ In the Figure the equity premium is increasing in the fluctuation aversion measure $1 / I E S$ in both cases, but the curve that holds $R A C$ constant is flatter. This suggests that part of the explanation for the role of the fluctuation aversion measure is in its role in determining $R A C$. But this is only a partial explanation: The equity premium is increasing in $1 / 1$ IES even when we hold $R A C$ constant.

\footnotetext{
${ }^{7}$ Note that (13) implies that when the $R A C$ is constant, the $R A M$ coefficient changes and is given by: $R A M=(1 / \eta)(R A C-(1-\eta)(1 / I E S))$.
} 


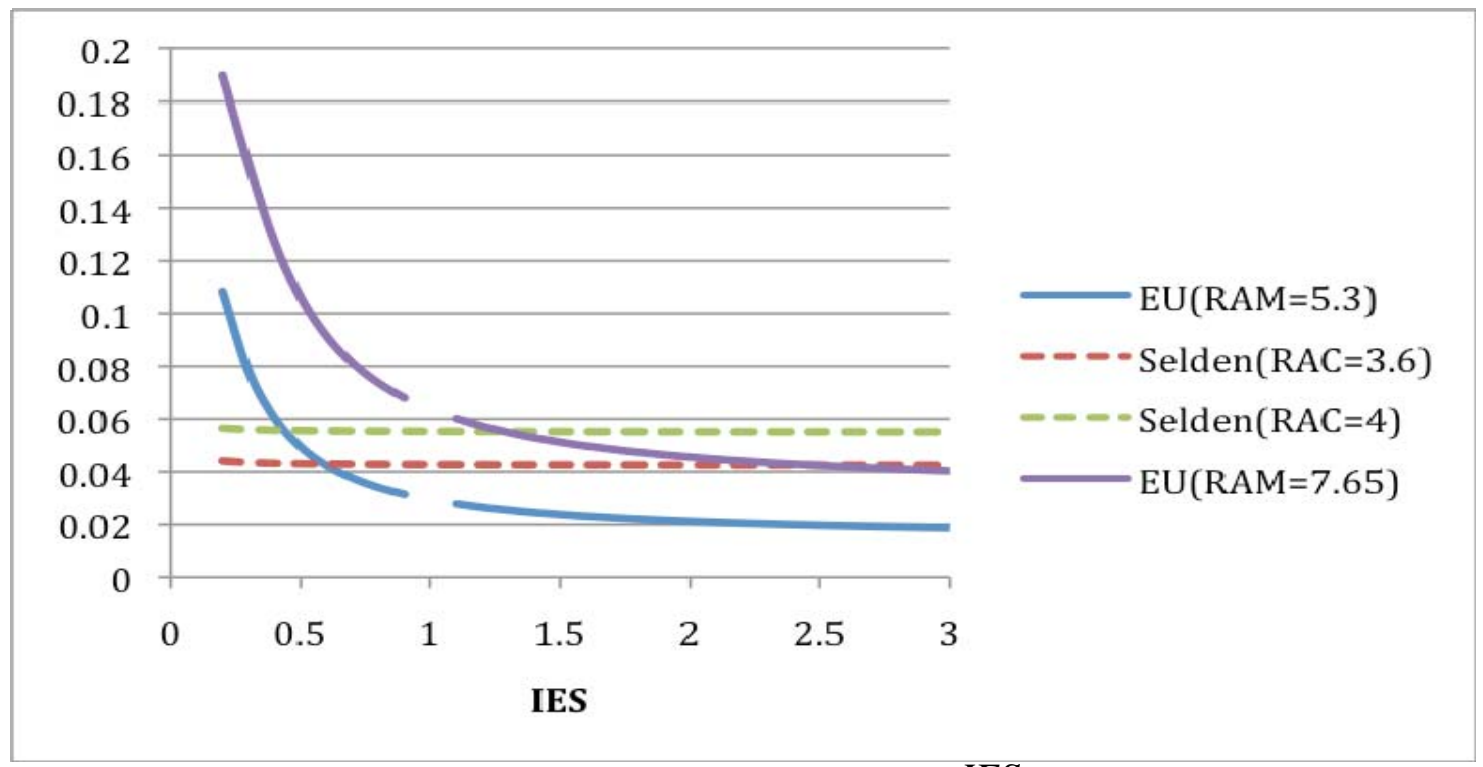

a. Equity Premium as a function of IES

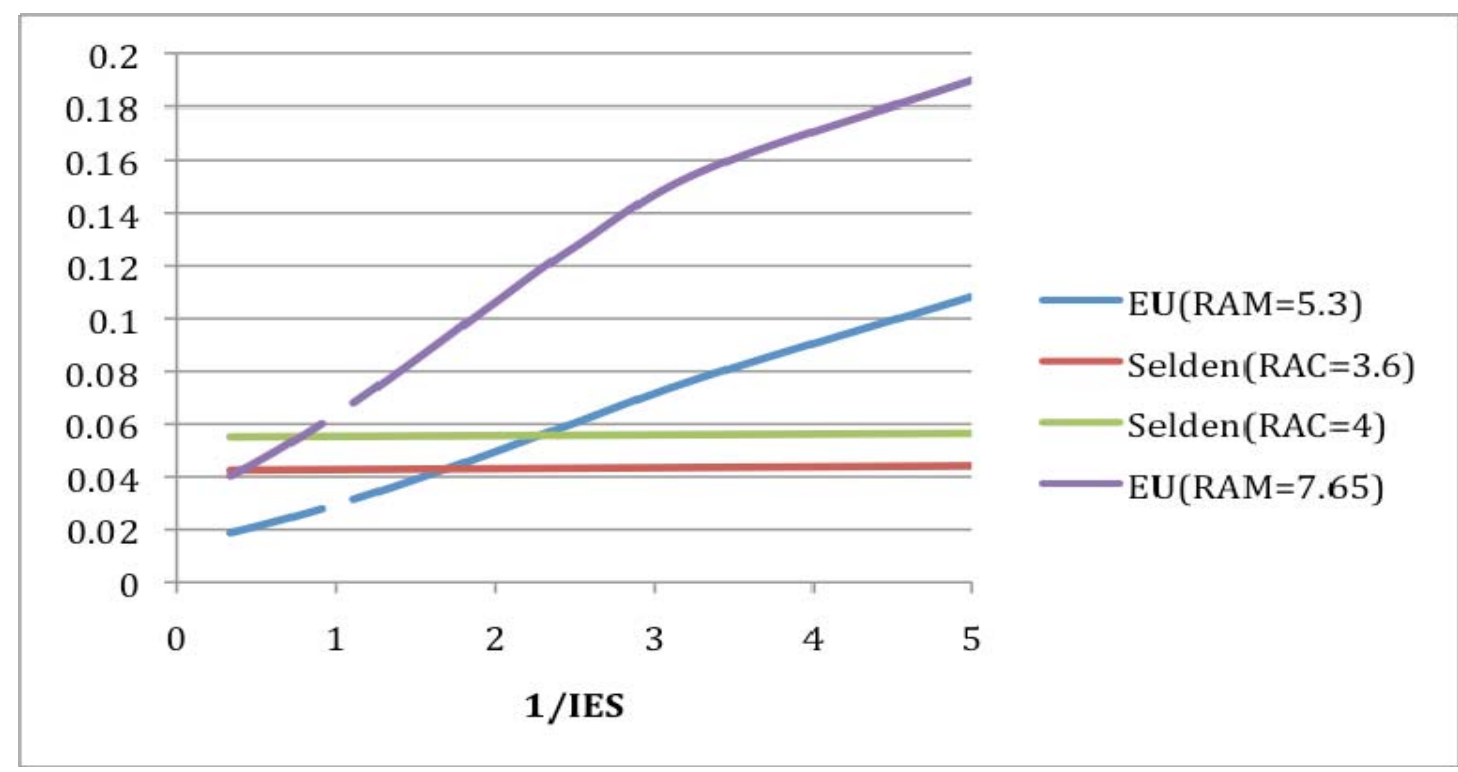

b. Equity Premium as a function of $1 / I E S$

Figure 7: Equity Premium when $R A C=(3.6,4)$ for Selden and $R A M=(5.3,7.65)$ for $K M$ expected utility 
25

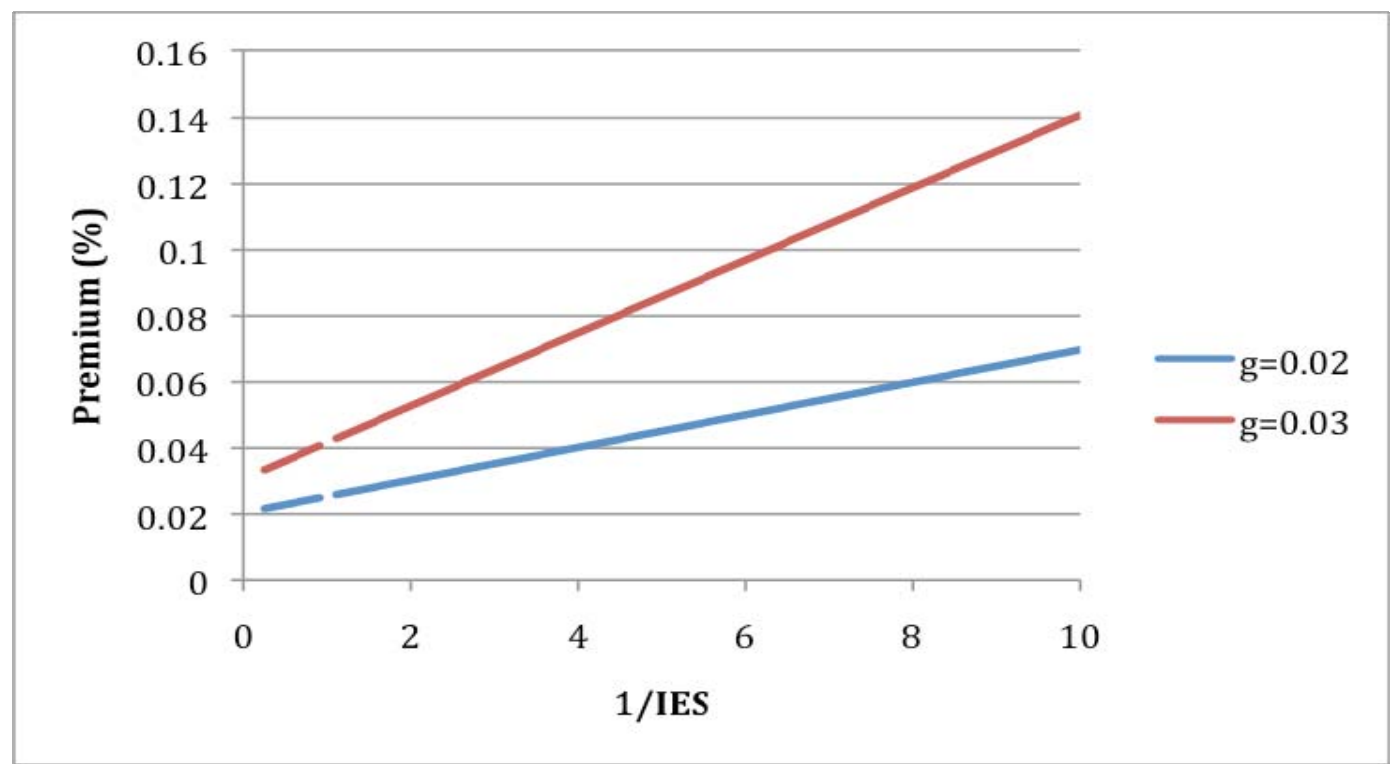

Figure 8: The Fluctuations Premium as a function of the Fluctuations Aversion measure ( $1 / 1$ IES $)$ under expected utility when consumption is: $\left(C_{0}=1, C_{1}=1+g\right)$. 


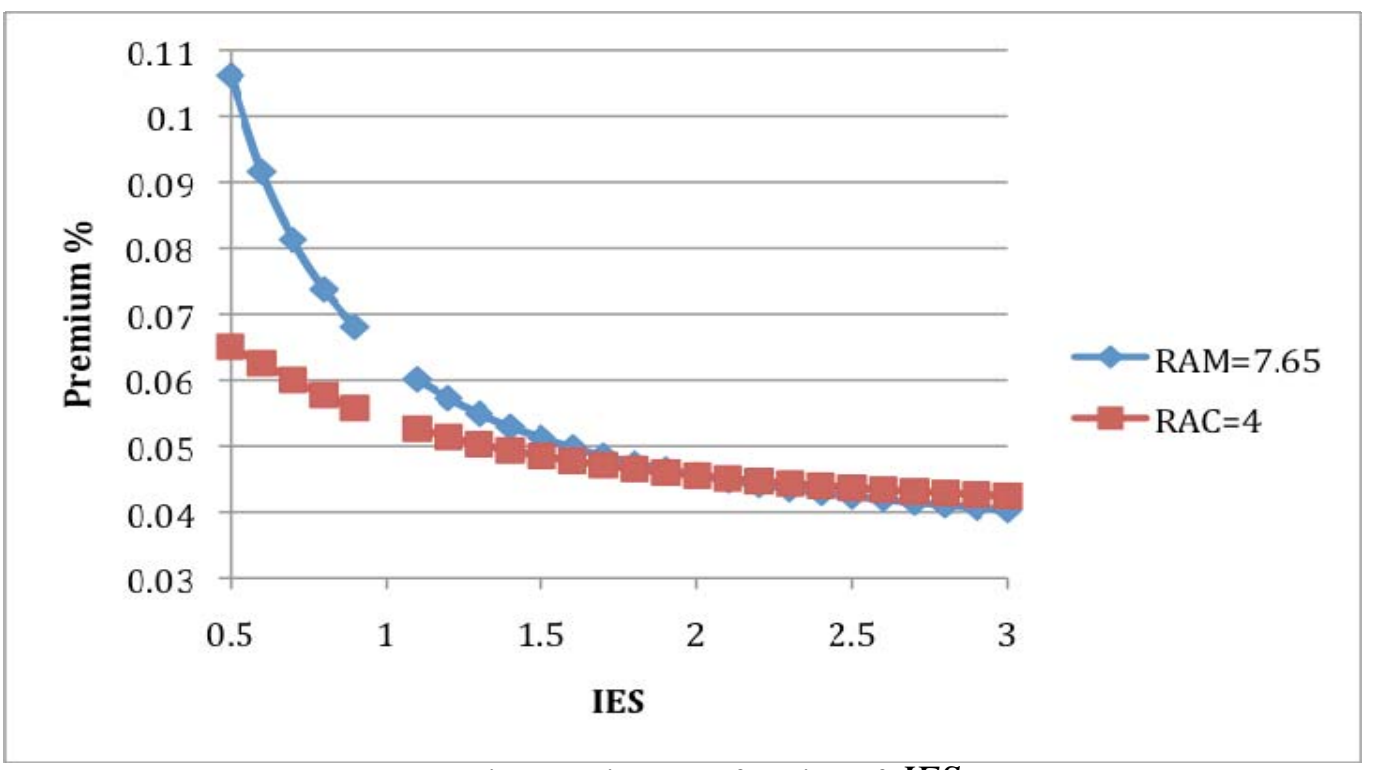

a. Equity Premium as a function of IES

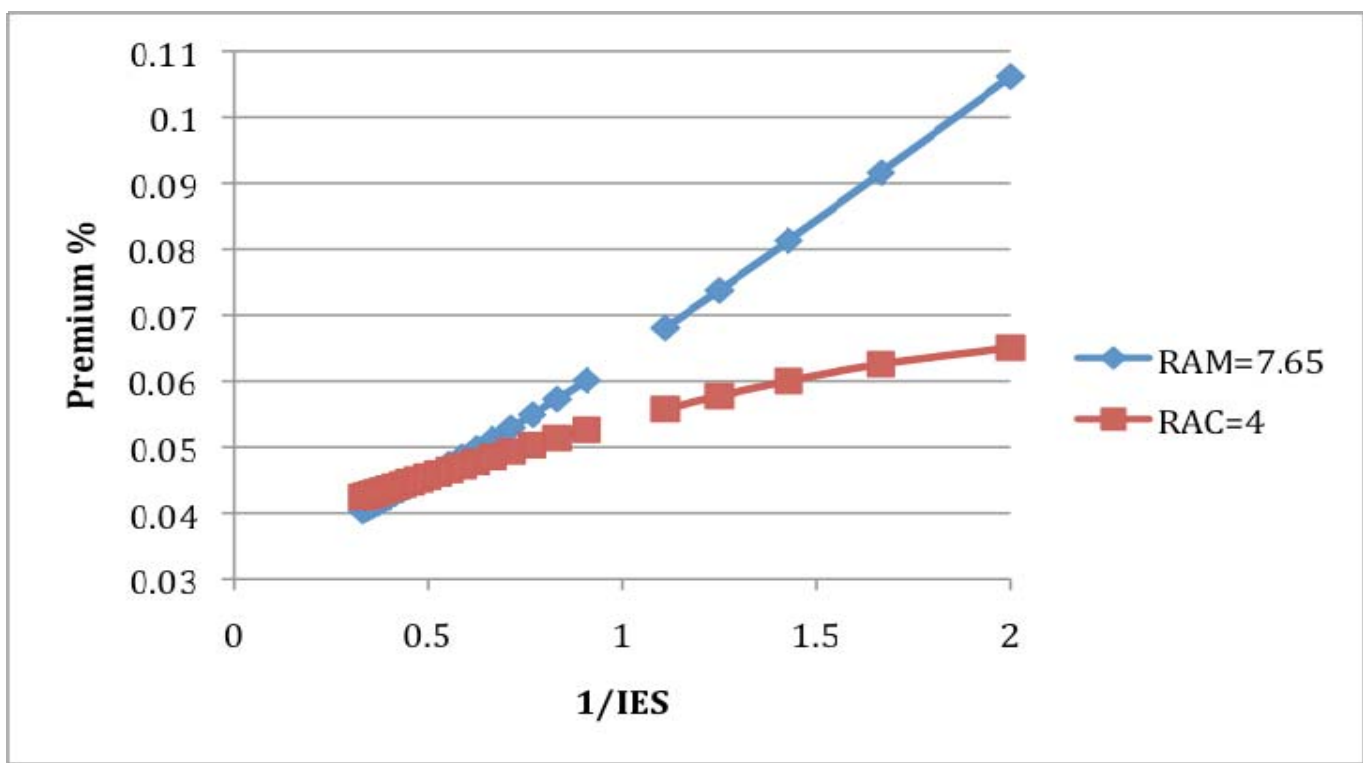

b. Equity Premium as a function of $1 / 1 E S$

Figure 9: The Equity Premium under expected utility holding (a) $R A C$ constant and (b) $R A M$ constant. 


\section{VARYING $\beta$}

In the calibration exercise I assumed $\beta=0.96$. This is the standard choice when the representative agent lives forever but it is not clear that this is a good choice for an overlapping generations economy. We can imagine for example that the second period wealth is spent on many future periods and as a result $\beta$ is large. To examine this hypothesis I now vary $\beta$ and choose the one that can hit the target with the lowest $R A M$ coefficient. This measure of the "goodness of fit" uses the prior that RAM is low. Table 1 makes the calculations for various choices of IES. Surprisingly, the "best" $\beta$ is close to 0.96 and whenever the "best" beta is not equal to 0.96 , the improvement in the $R A M$ coefficient is small.

Table 1: Searching for the "best" $\beta$

\begin{tabular}{|r|r|l|r|}
\hline & $R A M(\beta=0.96)$ & "best" $\beta$ & \multicolumn{1}{|c|}{ RAM("best" $\beta)$} \\
\hline$I E S=2$ & $8.3(4.3)$ & 0.97 & $7.9(4.1)$ \\
\hline$I E S=1.1$ & $7(3.9)$ & 0.96 & $7(3.9)$ \\
\hline$I E S=0.5$ & $5.3(3.6)$ & 0.96 & $5.3(3.6)$ \\
\hline$I E S=0.25$ & $4.1(4)$ & 0.98 & $3.8(4)$ \\
\hline$I E S=0.2$ & $4.1(4.6)$ & 0.99 & $3.5(4.6)$ \\
\hline
\end{tabular}

Note: $R A C$ in parentheses. The "best" $\beta$ is the $\beta$ that allows us to hit the target with the lowest $R A M$ coefficient.

\section{CONCLUDING REMARKS}

The predictions of the $K M$ expected utility seem very different from the predictions of the Selden utility function. Part of the difference may be explained by interpreting the cardinal risk aversion measures. 
Cardinal risk aversion measures can be eliminated under monotone increasing transformations. The Selden cardinal risk aversion measure, $R A C=1-\sigma$, characterizes the attitude towards bets on future consumption. The expected utility cardinal risk aversion measure, $R A M=1-\psi$, characterizes the attitude towards money bets. The comparable $R A C$ measure for the expected utility function is a weighted average of the fluctuations aversion measure $1 / 1$ IES and the cardinal risk aversion measure $R A M$. The difference in the predictions of the two approaches are much smaller when using parameters that imply the same comparable $R A C$ measures.

There are however, some qualitative differences. Under expected utility, the fluctuations aversion measure $1 /$ IES plays an important role in the determination of the equity premium. This role cannot be fully explained by the role of $1 / I E S$ in the determination of the RAC measure: The equity premium is increasing in $1 /$ IES even when holding RAC constant. Under the Selden utility function the IES play no role in the determination of the equity premium.

A related qualitative difference is in the applicability of first order stochastic dominance. Under expected utility, we can use first order stochastic dominance to predict the attitude towards some bets from the information that is in the indifference map. This is not possible under the Selden utility function.

Our overlapping generations model with $K M$ expected utility function predicts rates of return that are on target when using $I E S=2$ and $R A C=4(R A M=7.65)$. In this sense the results in Barro (2009) are robust. But the welfare cost estimates are different. When $(I E S=2, R A M=7.65)$, I get a welfare cost estimate of $0.6 \%$ that is large, but is an order of magnitude smaller than the $24 \%$ welfare cost estimated by Barro. I do not think that this difference arises because of the use of the Epstein-Zin-Weil approach because the welfare estimates I get when using the 2 period version of this approach are also small in comparison to Barro. The difference in the estimated welfare cost is probably due to the difference in the horizon of the representative agent. In our overlapping 
generations model the economy lasts forever but agents live for two periods and the stochastic process that governs the productivity of each generation $\left(\lambda_{t}\right)$ does not affect any of the results. In Barro's model the representative agent lives forever and he is therefore sensitive to long run risk that arises as a result of a random walk consumption (productivity) process. Both the 2 periods horizon and the infinite horizon seem highly unrealistic. This suggests a more general overlapping generations model with finitely lived individuals as a project for future research.

It may be worthwhile to point out that extending the $K M$ expected utility function to more than 2 periods horizon does not lead to time inconsistency problems. See the Appendix in Eden (2008). It leads however to marginal rates of substitution that change with past consumption. This is not necessarily a "bad" feature because it implies changes in asset prices that are not caused by changes in the distribution of dividends. However, I do not think that this will contribute to solving the excess volatility puzzle because the effect of past consumption on the marginal rates of substitution seems small.

\section{REFERENCES}

Bansal Ravi and Amir Yaron., "Risks for the Long Run: A Potential Resolution of Asset Pricing Puzzles" The Journal of Finance, Vol. LIX, No.4, August 2004, pp.1481-1509.

Barro Robert, J. "Rare Disasters, Asset Prices, and Welfare Costs" American Economic Review, 2009, 99:1,243-264.

Beaudry Paul and Eric van Wincoop. (1996). "The Intertemporal Elasticity of Substitution: An Exploration using a US Panel of State Data" Economica, 63, 495-512.

Campbell, J. and Mankiw, G. (1989). Consumption, Income and Interest Rates: Reinterpreting the Time Series Evidence". In O.Blanchard and S. Fischer (eds), NBER Macroeconomic Annual 1989, 185-216. Cambridge, MA. NBER.

Eden, Benjamin., "The Role of Insurance Gambling in Allocating Risk Over Time," Journal of Economic Theory, Vol. 16, No. 2, December 1977, pp. 228-246. 
"Substitution, Risk Aversion and Asset Prices: An Expected Utility Approach" Vanderbilt University, Department of Economics WP\# 08-W03, January 2008.

Epstein Larry G. and Stanley E. Zin "Substitution, Risk Aversion, And the Temporal Behavior of Consumption and Asset Returns: A Theoretical Framework" Econometrica, Vol. 57, No.4 (July, 1989), 937-969. "Substitution, Risk Aversion, And the Temporal Behavior of Consumption and Asset Returns: An Empirical Analysis" Journal of Political Economy, 1991, Vol.99, no.2, 263-286.

Hall, R.E. (1988). "Intertemporal Substitution in Consumption" Journal of Political Economy, 96, 339-57.

Kihlstrom Richard E. and Leonard Mirman., "Risk Aversion with Many Commodities" Journal of Economic Theory 8, 361-388 (1974).

McGrattan E.R. and Prescott E.C., "Average Debt and Equity Return: Puzzling?" American Economic Review, Papers and Proceedings, 93(2): 392-397, 2003.

Lucas, Robert E., Jr. "Asset Prices in an Exchange Economy", Econometrica, 1978, Vol. 46(6), pp. 1426-1445.

"Macroeconomic Priorities" The American Economic Review, Vol. 93, No.1 (March 2003), 1-14.

Mehra, R. and E.C. Prescott., "The equity premium: A puzzle" Journal of Monetary Economics, 15 (1985), 145-161.

Selden, Larry. "A New Representation of Preferences over 'Certain $\times$ Uncertain' Consumption Pairs: The 'Ordinal Certainty Equivalent' Hypothesis." Econometrica 46 (Sep. 1978), 1045-60.

Van den Heuvel Skandar "Temporal Risk Aversion and Asset Prices" Preliminary and incomplete draft, October 2007.

Vissing-Jorgensen Annette and Orazio P. Attanasio., "Stock-Market Participation, Intertemporal Substitution, and Risk-Aversion", American Economic Review, Papers and Proceedings, May 2003, 383-391.

Weil P., "The Equity Premium Puzzle and the Risk Free Rate Puzzle" Journal of Monetary Economics 24 (1989),401-21.

"Nonexpected Utility in Macroeconomics" Quarterly Journal of

Economics 105 (1990) 29-42. 